\title{
Autophagy Overactivity Regulate Terf1 and Terf2 in Positive and Negative-Telomerase Cancer Cell Lines
}

mohammad panahi ( $\nabla$ mohammad.panahi.ali110@gmail.com)

Pasteur Institute of Iran https://orcid.org/0000-0002-1045-1097

Saeed Samani

Tehran University of Medical Sciences

Nasrin Mohajeri

Pasteur Institute of Iran

Akram Sadat Tabatabee Bafroee

Islamic Azad University

Kazem Baesi

Iranian Institute of Philosophy

Asghar Abdoli

Pasteur Institute of Iran

\section{Research Article}

Keywords: Autophagy, Beclin1, Cancer, Terf

Posted Date: November 30th, 2021

DOI: https://doi.org/10.21203/rs.3.rs-1102455/v1

License: (c) (i) This work is licensed under a Creative Commons Attribution 4.0 International License.

Read Full License 


\section{Abstract}

A recent suggestion for cancer therapy is targeting intracellular homeostatic signaling pathways like autophagy providing the balance between metabolism and cell cycling. Our study focused on investigating the relationship between autophagy activation by Beclin 1 transfection and assessing Terf 1 and Terf2 expression as shelterin proteins. The beclin1-containing plasmid was introduced to the U-2OS and Huh7 cell lines using Lipofectamine. The LC3-II as an intracellular autophagosomal marker was detected in transfected cells by flow cytometry. Also, the cells were treated with 3-methyladenine and metformin as autophagy inhibitors and inducers, respectively. Finally, the expression levels of Terf1 and Terf2 were analyzed by real-time PCR. Fluorescent images and flow cytometry results proved excellent GFP expression in the transfected cells. The results of real-time PCR demonstrated that autophagy induction by Beclin1 was increased Terf 1 expression level in U-20S cells up to $451 \%$, while Huh7 cells suffered from the decreased expression of Terf1. Altogether, Terf2 expression was enhanced significantly in both cell lines after $48 \mathrm{~h}$ treatment in comparison with $24 \mathrm{~h}$ treatment. The obtained data provided that Beclin1-based activation of autophagy leads to overexpression of some protective shelterin proteins.

\section{Introduction}

Cancer as an uncontrollable cell division phenomenon results from disruption of the cell metabolism, cell cycle, and cell death signaling [1]. Some specific signaling pathways might be helpful to administer suitable drugs against cancer. Therefore, a development of medicines associated with cell death pathways seems worthwhile [2-5]. Nowadays, identifying and targeting critical points in a signaling pathway are among the most important research goals for cancers therapy. Unambiguously, much attention has been paid to signaling pathways of cell energy and cell longevity $[6,7]$.

Autophagy or basal autophagy as a conserved intracellular process during evolution is used by the cells to clear and digest the affected organelles, folded-down or degraded proteins, and intracellular pathogens $[8,9]$. Therefore, it is necessary to replace the damaged cells with new ones and keep natural vitality [10]. Additionally, the basal autophagy signaling pathway has a directly connects with intracellular energy, cell cycle, and cell longevity [11]. Beclin 1 is the first identified gene in the mammalian autophagy pathway that organizes the Phosphatidylinositol 3-kinase catalytic subunit type 3 complex (PI3KC3) and activates the autophagy process $[12,13]$.

Basal autophagy plays two contradictory functions in cancer: as a cancer suppressor or supporter, depending on the oncogenes and cancer progression stage [14]. The cancer progression stage and the active oncogenes in each stage are important issues to decide for cancer therapy [6]. According to literature review, tumor suppressor genes (ARF tumor suppressor (p14Arf), Liver kinase B1 (LKB1), Tuberous sclerosis1/2 (TSC1/2), Phosphatase and tensin homolog (PTEN), and Tumor protein 53 (p53)) have positive adjustment effects on autophagy, while mammalian target of rapamycin (mTOR)/PI3K/ Protein kinase B (AKT or PKB) pathway oncogenes have a negative effect on the basal autophagy [15, 16]. As a cancer suppressor, basal autophagy prevents cancer progression in the early stages of cancer 
by removing damaged organelles, oncogenic protein substrates, and toxic unfolded proteins $[17,18]$. On the contrary, basal autophagy dysfunction in cancer may cause damages to DNA and raise genes transcription, causing acceleration in carcinogenesis. Therefore, basal autophagy suppression can act as a pathway for cancer stability $[15,16,19]$. Due to the dual role of basal autophagy in cancer progression or cancer therapy, the main point is that what progress stages and related oncogenes should be considered to decide to increase or decrease autophagy activity.

On the other hand, the telomere length can control the longevity in normal cells and it is shortened during every cell division, which causes starting cell death signaling after reaching a critical size [20]. A telomere is a nucleoprotein structure at the end of the linear chromosomes, which is made of repetitive sequences of 5-TTAGGG-3, shelterin Telomeric repeat-binding factor1, Telomeric repeat-binding factor2 (Terf1, Terf2), Protection of telomeres protein 1 (POT1), TERF1-interacting nuclear factor 2 (TINF2), Rasproximate-1 or Ras-related protein 1 (Rap1), Tripeptidyl peptidase 1 (TPP1), and non-shelterin complex proteins [21]. Telomere preservation is essential in cancer cells, and telomere length is preserved by Alternative lengthening of telomeres (ALT system). Therefore, the cancer cells are divided into positive telomerase and negative-telomerase (positive ALT) types [22, 23].Telomerase regulation is increased in about $85 \%$ of cancers (positive telomerase) in contrast to the remaining cancers (positive ALT) in which the shelterin protein expression is positive [24,25].They are potential oncogenes in different stages of cancer that conserve telomeres and cause cell survival [26, 27].

The ALT system consists of shelterin proteins, including Terf1 and Terf2, that maintain the telomere length to a specific limit [28, 29]. Terf1 and Terf2 are the members of the myeloblastosis (Myb) superfamily, which can transcribe DNA, have physical connections with Telomeric repeat-containing RNA (TERRA), and can behave as a polymerase [30,31]. Altogether, Terf 1 and Terf2 are the primary oncogene candidates among the shelterin proteins due to their telomerase-like activity and the possible interaction of Terf2 with p53 [32, 33].

Also, all kinds of cancer cells can escape type one (apoptosis) and type two (autophagy) cell deaths. Therefore, the connection between cell survival and autophagy remains a critical challenge in cancer therapy [34,35]. Thus, the accurate identification of autophagy effects on different stages of cancer and different positive and negative-telomerase cancer cells helps us to a better understanding the autophagy effects in every stage of cancer [36]. The result of our previous study has suggested that the autophagy induction leads to reduce telomerase activity in positive-telomerase HeLa cell line [37]. Now, the essential question that we tried to answer in our current study was to evaluate the effects of autophagy overactivation on positive and negative-telomerase cancers via the ALT system.

According to the previous and present studies, we found that autophagy overactivity increases Terf 1 and Terf2 expression and reduces telomerase activity. Based on the classification, cancer cells can be divided into positive-telomerase (negative-ALT) and negative-telomerase (positive-ATL). In addition, the malignancy effects of autophagy overactivity on positive-telomerase cell lines such as Huh7 depend on cancer development. However, in any case, autophagy overactivity causes malignancy in positive-ALT cell 
lines such as U-2OS. Taken together, our results provide supporting evidence for resolve ambiguity autophagy's dual role and find the best treatment that fits the type of cancer.

\section{Materials And Methods}

\subsection{Authentication of cell lines}

Huh7 (NCBI NO. C158) and U-20S (NCBI NO. C555) cells were provided by the Cell Bank, Pasteur Institute of Iran. All cell lines identity was authenticated by Isoenzyme analysis and routinely screened for mycoplasma absence. All cell lines were propagated upon receipt/authentication and frozen $\left(-80^{\circ} \mathrm{C}\right)$ in aliquots.

\subsection{Beclin1 transfection and treatment of the cells}

To investigate the impact of Beclin1 on autophagy activation, the target cell lines were treated by Beclin1containing plasmid as the main treatment. The pcDNA3.1 $1^{(-)}$plasmid, consisting of the human Beclin1 sequence gene (NM-003766.3), was prepared in our previous study [36]. The cells were cultured using DMEM (Gibco, USA) supplemented with 10\% FBS (Gibco, USA), penicillin (100 units/ml), and streptomycin $\left(100 \mu \mathrm{g} / \mathrm{ml}\right.$, Gibco, USA) in an $80 \%$ humidified incubator with $5 \% \mathrm{CO}_{2}$. The cells were harvested at 70-90\% confluency and used in suspend transfection. The cell viability was carried out by trypan blue staining. The cells were seeded in a 6-well plate $\left(1 \times 10^{6} \mathrm{cell} / \mathrm{ml}\right)$ (suspended in sterile DMEM without FBS and antibiotic). The cells were transfected by Lipofectamine 2000 (Invitrogen, USA) according to the manufacturer's instruction and incubated for 24 and $48 \mathrm{~h}$ in the same condition.

\subsection{Alternative treatments by Lipofectamine, 3-methyladenin, and metformin}

3-methyladenin (Sigma-Aldrich, USA) at ten mM and metformin (Sigma-Aldrich, USA) at $20 \mathrm{mM}$ concentrations as non-toxic concentrations determined by MTT assay, was used as the autophagy inhibitor and inducer, respectively. At 70-90\% cellular confluency, the complete culture medium was replaced with the 3-methyladenin and metformin solutions, separately and incubated for 24 and $48 \mathrm{~h}$ under the same cell culture conditions. As lipids and their metabolizing enzymes have an important role in autophagy, the influence of Lipofectamine was studied on both cell lines.

\subsection{Detection of LC3-II as an intracellular autophagosomal marker}

Anti- Microtubule-associated protein 1A/1B-light chain 3 (LC3-II) (ab48394) and Goat Anti-Rabbit IgG Fc (FITC) pre-adsorbed (ab98466) were acquired from Abcam, as primary and secondary antibodies, respectively. After transfection by Beclin 1 for $48 \mathrm{~h}$, the cells were fixed by $0.01 \%(\mathrm{v} / \mathrm{v})$ formaldehyde for 10-15 min, and permeabilized with Tween $20(0.5 \%(\mathrm{v} / \mathrm{v})$ in Phosphate-buffered saline (PBS). Then, the cell lines were tagged using anti-LC3-Il antibody diluted in $1 \%(\mathrm{w} / \mathrm{v})$ Bovine serum albumin (BSA) with agitation for $1 \mathrm{~h}$ at room temperature. After three washes with PBS, the labeled cells were incubated for $1 \mathrm{~h}$ 
with FITC-conjugated secondary antibody diluted in 1\% (w/v) BSA. Ultimately, the formation of LC3-IIpositive structures was estimated by the percentage of stained cells using flow cytometry.

\subsection{Real-time PCR assay}

Human Terf1 (NM_017489.2) and Terf2 (NM_005652.4) sequences were taken from the NCBI database to design forward and reverse primers (Table 1). $\beta$-Actin (Human ACTB primer/Double-dye probe mix, Primer Design, England) was used as the reference gene.

According to the manufacturer's instructions, total RNA was isolated using guanidinium isothiocyanate (Yekta Tajhiz Azma, Iran) and total RNA was treated by DNase (Sigma-Aldrich, USA). The RNA integrity and purity were checked and 260/280 and 260/230 ratios were close to 2 . The One-Step TB Green PrimeScript RT-PCR Kit II (Takara, Japan) was used for cDNA synthesis from RNA using PrimeScript Reverse Transcriptase and PCR amplification. The amount of the reaction was $10 \mu \mathrm{l}$ and contained $5 \mu \mathrm{l}$ of SYBR Green buffer, $0.1 \mu \mathrm{l}$ forward primer, $0.1 \mu \mathrm{l}$ reverse primer, $0.3 \mu \mathrm{l}$ Taq polymerase enzyme, $0.5 \mu \mathrm{l}$ RNA template, and $4.0 \mu \mathrm{LEPC}$ water. After Taq polymerase activation at $42^{\circ} \mathrm{C}$ for $15 \mathrm{~min}$, the second hold in real-time PCR was started at $95^{\circ} \mathrm{C}$ for $10 \mathrm{~s}$ in a Rotor-Gene 6000 Series System followed by 40 cycles of $95^{\circ} \mathrm{C}$ for $5 \mathrm{~s}$ and $62^{\circ} \mathrm{C}$ for the $30 \mathrm{~s}$. Subsequently, the visualized fluorescent signals were analyzed with Rotor-Gene 6000 Series Software 1.7 and gene expression was evaluated based on the threshold cycle (Ct) and using the REST 2009 software (QIAGEN). Each sample was analyzed at least in triplicate.

\section{Results}

\subsection{Transfection efficiency evaluation}

The successful Beclin1 transfection in U-20S and Huh7 cells was proved by fluorescence microscopy (Fig. 1) and the percentage of Green fluorescent protein (GFP) transfection was accurately calculated by flow cytometry (Fig. 2). In both cell lines, the best transfection efficiency was obtained in quantities 400 $700 \mu \mathrm{g} / \mathrm{ml}$ of DNA and 6-10 $\mu \mathrm{l}$ of Lipofectamine 2000. Flow cytometry quantitative results showed that the expression of Beclin1 in cell lines was 40-70 percent. The GFP expression in control groups was less than $2 \%$ and more than $40 \%$ in transfected U-2OS and Huh7 cells, respectively.

\subsection{Autophagy induction by exogenous Beclin1}

Flow cytometry results (Fig. 3) demonstrated that the exogenous Beclin1 caused an increase in autophagy activity with $69.8 \%$ in U-2OS and $65.34 \%$ in Heh7 cells sorting by LC3-II positive.

\subsection{Assessment of Terf1 and Terf2 expression level}

The expression levels of Terf1 and Terf2 are shown in Fig. 4 and 5, respectively. According to Fig. 4, except with 3-methyladenin treatment which would be expected, other treatments, particularly Beclin1 transfection, caused an increase in EL of Terf1 in U-20S after 48h up to $451.1 \%$ for Beclin1-containing 
plasmid. The expression level of Terf1 decreased by $9.9 \%$ under 3-methyladenin treatment after $48 \mathrm{~h}$. Variations of Terf1 expression levels for the Huh7 cell line were opposite to U-20S except for 3methyladenin treatment which was similar. Although a decrease in expression level after $48 \mathrm{~h}$ in comparison with $24 \mathrm{~h}$ expression was not considerable, it would be expected that treatments for a longer time might lead to lower expression levels. Terf2 expression had similar variations for both U-20S and Huh7 cell lines (Fig. 5). The different treatment for $24 \mathrm{~h}$ led to a significant improvement in the expression level for all treatments that could have a positive effect on Terf2 upregulation. 3-methyladenin treatment displayed its intrinsic and expectative downregulating effect on Terf2 expression, which resulted in a $31.4 \%$ and $33.1 \%$ decrease in Terf2 expression level for U-20S and Huh7 cells, respectively.

\section{Discussion}

Cancer cells are categorized into malignant and benign, in which the malignant cancer cells are classified into positive and negative-telomerase. Besides, there are four stages to transform a normal cell into a metastatic form: 1) carcinogenesis, 2) tumorigenesis (stabilization and development of cancer cells), 3) malignancy, and 4) metastasis [1].

Basal autophagy is active in all eukaryotic cells to maintain cell homeostasis [38]. Basal autophagy has shown a dual role in carcinogenesis, tumorigenesis, and tumor progression, which depends on the active oncogenes, type of cancer, and the stage of carcinogenesis, tumorigenesis, and malignancy [39, 40]. At the beginning of carcinogenesis and tumorigenesis, basal autophagy restrains cancer progress, but causes malignancy and metastasis after cancer stability [15]. In the early stage of malignancy, tumor cells are dividing, and a slight increase in the basal autophagy rate causes the stability of tumor cells because it maintains the cell cycle by p53 pathway inhibition $[1,41]$. Also, starvation, anorexia, and other stressful situations increase the basal autophagy rate slightly in stable malignant tumor cells and supply cell energy that causes increased longevity of malignant tumor cells [42].

In this study, autophagy activation increased by Beclin 1 overexpression and induction by metformin and decreased by 3-Methyladenine [43-45]. An increase or decrease in autophagy activation should be sudden to involve the whole-cell organs, especially the mitochondria as the center of energy [46, 47]. Terf1 and terf2 protein levels can be detected as Double-strand DNA break (DSB) molecular markers, because they are common in positive and negative-telomerase cells [48]. We detected LC3-II as an intracellular autophagy marker in U2OS cells (69.8\%) and Huh7 cells (65.35\%). The results of the real-time PCR assay indicated that autophagy induction along with Beclin1 transfection raised Terf1 expression in U2OS and Terf2 expression levels in both U2OS and Huh7 cell lines. Thus, it seems that there is a correlation between the Beclin1-related autophagy pathway and Terf1/Terf2 expression. Metformin treatment raised Terf1 in U2OS and Terf2 expression levels in both U2OS and Huh7 cell lines. Besides, 3-Methyladenine treatment decreases Terf1 and Terf2 in both U2OS and Huh7 cells. Terf2 as a member of the ALT system, has an inhibitory effect on telomerase which blocks the telomerase pathway in the long telomeres [25]. Therefore, in positive-telomerase cell lines such as HeLa and Huh7, it can be inferred that the effects of decreasing or increasing autophagy activation depend on the cancer stage, and control of cell cycle on 
oncogenes. Usually, the ALT complex (Terf1, Terf2, POT1, TIN2, Rap1, and TPP1) is more active in negative-telomerase cancer cell lines, and can renovate the telomere when its length reaches a critical level. Consequently, autophagy activation in BET-3M, SUSM-1, Saos-2, and U-2OS cell lines which are negative-telomerase and positive-ALT, induces carcinogenesis and tumorigenesis by the increase of Terf2 expression $[49,50]$. Although autophagy dysfunction can start carcinogenesis, it is not enough for malignancy because malignancy occurrence in this pathway depends on other oncogenes such as p53/ Auxin response factors (ARF)/ Ataxia-telangiectasia mutated (ATM) (Fig. 6).

It has been proved that Terf2 is responsible for suppressing ATM kinase. On the other hand, deletion or inhibition of Terf2 creates DSB, which activates the ATM kinase pathway that arrests the cell cycling by p53 at the end of the chromosomes in mice and humans [51]. Thus, a decrease in Terf2 causes an increase in ATM serine/threonine kinase, and finally, activates p53 [32, 52]. Indeed, if the p53 gene mutates, cell cycling will not be arrested, and some oncogenes such as p53 are present when normal cells are transformed to malignancy and metastasis cells (Fig. 6, pathway 2).

Since most of these oncogenes are cell cycling and energy level control factors, they usually cooperate with the autophagy and apoptosis pathways. Furthermore, Terf2 is the telomeric preserving factor, which has an inverse relationship with telomerase and an increase in autophagy activation causes overexpression of Terf2 and Terf1 [53]. Hence, overexpression of Terf2 and Terf1 was expected in Beclin1containing plasmid, metformin, and Lipofectamine treatments $[54,55]$. According to the data, in the early stages of positive-telomerase cancer, when there is a cell cycling control oncogene such as p53, autophagy down-regulation is recommended, because it reduces cell energy level and cell division. However, when there is no cell cycling control oncogene, autophagy up-regulation is recommended, because it harms the mitochondria and cell cycling regulations. Nevertheless, in cancer stability stages, it is recommended to reduce autophagy. Anyway, an enhancement of autophagy activation causes malignancy and metastasis in negative-telomerase (positive-ALT) cells [4, 5]. Thus, in positive-ALT cancer, a decrease in autophagy activity is recommended in all cancer stages. Eventually, it is logical to say that autophagy is the cause to form some cancer cells. The autophagy pathway is probably an Achilles heel in malignancy which needs further detailed study.

\section{Conclusion}

This study focused on the correlation between autophagy activity and Terf 1 and Terf2 expression levels in U-20S and Huh7 cell lines. The second type of cell death or autophagy is the intracellular autolysis process, which protects the cell metabolism pathways. According to the studies, the rise in Beclin1 expression increases autophagy activation and consequently decreases telomerase activity. The results of flow cytometry and fluorescent microscopy revealed satisfying expression of Beclin1 in both cells. Also, real-time PCR results indicated that autophagy induction using Beclin1-containing plasmid increased Terf 1 and Terf 2 expression levels in U-20S cells. Although all treatments possibly affecting on the expression of Terf genes caused up-regulation of Terf2 in the Huh7 cell line, their Terf1 expression level lowered after 48h. Also, the results demonstrated a relationship between Beclin1 expression and 
activation of the autophagy pathway. We hope this research and future studies help identify cancer controlling factors and choosing an appropriate treatment regimen for a cancer progression stage.

\section{Abbreviations}

3MA: 3-methyladenine

ALT: Alternative lengthening of telomeres

AKT or PKB: Protein kinase B

ARF: Auxin response factors

ATM: Ataxia-telangiectasia mutated

BSA: Bovine serum albumin

DSB: Double-strand DNA break

GFP: Green fluorescent protein

LC3: Microtubule-associated protein 1A/1B-light chain 3

LKB1: Liver kinase B1

mTOR: Mammalian target of rapamycin

Myb: Myeloblastosis

P14ARF: ARF tumor suppressor

P53: Tumor protein 53

PBS: Phosphate-buffered saline

PI3KC3: Phosphatidylinositol 3-kinase catalytic subunit type 3 complex

POT1: Protection of telomeres protein 1

PTEN: Phosphatase and tensin homolog

Rap1: Ras-proximate-1 or Ras-related protein 1

Terf: Telomeric repeat-binding factor

TERRA: Telomeric repeat-containing RNA 
TINF2: TERF1-interacting nuclear factor 2

TPP1: Tripeptidyl peptidase 1

TSC: Tuberous sclerosis

\section{Declarations}

\section{Author contributions}

Mohammad Panahi: Conceptualization, Methodology, Writing - Original Draft, Validation

Saeed Samani: Validation, Software, Writing - Review \& Editing

Nasrin Mohajeri: Writing - Original Draft, Writing - Review \& Editing

Akram Sadat Tabatabee Bafroee: Investigation, Software

Kazem Baesi: Formal analysis, Project administration

Asghar Abdoli: Conceptualization, Supervision

\section{Data availability statement}

The data that supports the findings of this study are available on request from the corresponding author.

\section{Conflict of interest}

The authors declare that there are no conflicts of interest.

\section{Ethical approval}

Approved by Pasteur institute of Iran, IR.PII.REC.1395.105

\section{References}

1. Kerr DJ, Haller DG, van de Velde CJH, Baumann M (2016) Oxford textbook of oncology. Oxford University Press

2. Duffy A, Le J, Sausville E, Emadi A (2015) Autophagy modulation: a target for cancer treatment development. Cancer Chemother Pharmacol 75:439-447. https://doi.org/10.1007/s00280-014-2637-z

3. Levy JMM, Thorburn A (2011) Targeting autophagy during cancer therapy to improve clinical outcomes. Pharmacol Ther 131:130-141. https://doi.org/10.1016/j.pharmthera.2011.03.009 
4. Nehme G, Gordon N (2020) Autophagy in Osteosarcoma. In: Current Advances in the Science of Osteosarcoma. Springer, pp 167-175

5. Camuzard O, Santucci-Darmanin S, Carle GF, Pierrefite-Carle V (2019) Role of autophagy in osteosarcoma. J bone Oncol 16:100235. https://doi.org/10.1016/j.jbo.2019.100235

6. Li X, Xu H, Liu Y, et al (2013) Autophagy modulation as a target for anticancer drug discovery. Acta Pharmacol Sin 34:612-624. https://doi.org/10.1038/aps.2013.23

7. Yang ZJ, Chee CE, Huang S, Sinicrope F (2011) Autophagy modulation for cancer therapy. Cancer Biol Ther 11:169-176. https://doi.org/10.4161/cbt.11.2.14663

8. Mizushima N, Levine B (2010) Autophagy in mammalian development and differentiation. Nat Cell Biol 12:823-830. https://doi.org/10.1038/ncb0910-823

9. Yu L, Chen Y, Tooze SA (2018) Autophagy pathway: cellular and molecular mechanisms. Autophagy 14:207-215. https://doi.org/10.1080/15548627.2017.1378838

10. Doherty J, Baehrecke EH (2018) Life, death and autophagy. Nat Cell Biol 20:1110-1117. https://doi.org/10.1038/s41556-018-0201-5

11. Madrigal-Matute J, Cuervo AM (2016) Regulation of Liver Metabolism by Autophagy. Gastroenterology 150:328-339. https://doi.org/https://doi.org/10.1053/j.gastro.2015.09.042

12. Menon MB, Dhamija S (2018) Beclin 1 phosphorylation-at the center of autophagy regulation. Front Cell Dev Biol 6:137

13. Vega-Rubín-de-Celis S (2020) The Role of Beclin 1-Dependent Autophagy in Cancer. Biology (Basel) 9:4. https://doi.org/10.3390/biology9010004

14. Singh SS, Vats S, Chia AY-Q, et al (2018) Dual role of autophagy in hallmarks of cancer. Oncogene 37:1142-1158. https://doi.org/10.1038/s41388-017-0046-6

15. Rosenfeldt MT, Ryan KM (2011) The multiple roles of autophagy in cancer. Carcinogenesis 32:955963. https://doi.org/10.1093/carcin/bgr031

16. Kung C-P, Budina A, Balaburski G, et al (2011) Autophagy in tumor suppression and cancer therapy. Crit Rev Eukaryot Gene Expr 21:71-100. https://doi.org/10.1615/CritRevEukarGeneExpr.v21.i1.50

17. Chen $\mathrm{H}-\mathrm{Y}$, White $\mathrm{E}$ (2011) Role of autophagy in cancer prevention. Cancer Prev Res 4:973-983. https://doi.org/10.1158/1940-6207.CAPR-10-0387

18. White E, Mehnert JM, Chan CS (2015) Autophagy, Metabolism, and Cancer. Clin Cancer Res 21:50375046. https://doi.org/10.1158/1078-0432.CCR-15-0490 
19. White E (2012) Deconvoluting the context-dependent role for autophagy in cancer. Nat Rev cancer 12:401-410. https://doi.org/10.1038/nrc3262

20. Vera E, Bernardes de Jesus B, Foronda M, et al (2012) The Rate of Increase of Short Telomeres Predicts Longevity in Mammals. Cell Rep 2:732-737. https://doi.org/10.1016/j.celrep.2012.08.023

21. Louzon M, Coeurdassier M, Gimbert F, et al (2019) Telomere dynamic in humans and animals: Review and perspectives in environmental toxicology. Environ Int 131:105025.

https://doi.org/10.1016/j.envint.2019.105025

22. Zhang Y, Cai L, Wei R-X, et al (2011) Different expression of alternative lengthening of telomere (ALT)associated proteins/mRNAs in osteosarcoma cell lines. Oncol Lett 2:1327-1332. https://doi.org/10.3892/ol.2011.403

23. Stögbauer L, Stummer W, Senner V, Brokinkel B (2019) Telomerase activity, TERT expression, hTERT promoter alterations, and alternative lengthening of the telomeres (ALT) in meningiomas-A systematic review. Neurosurg Rev 43:1-8. https://doi.org/10.1007/s10143-019-01087-3

24. Günes C, Rudolph KL (2013) The role of telomeres in stem cells and cancer. Cell 152:390-393. https://doi.org/10.1016/j.cell.2013.01.010

25. Reddel RR (2003) Alternative lengthening of telomeres, telomerase, and cancer. Cancer Lett 194:155162

26. Fernandes SG, Dsouza R, Pandya G, et al (2020) Role of telomeres and Telomeric proteins in human malignancies and their therapeutic potential. Cancers (Basel) 12:1901. https://doi.org/10.3390/cancers12071901

27. Martinez P, Blasco MA (2010) Role of shelterin in cancer and aging. Aging Cell 9:653-666. https://doi.org/10.1111/j.1474-9726.2010.00596.x

28. Sobinoff AP, Pickett HA (2017) Alternative Lengthening of Telomeres: DNA Repair Pathways Converge. Trends Genet 33:921-932. https://doi.org/https://doi.org/10.1016/j.tig.2017.09.003

29. Cesare AJ, Reddel RR (2010) Alternative lengthening of telomeres: models, mechanisms and implications. Nat Rev Genet 11:319. https://doi.org/10.1038/nrg2763

30. Sfeir A, De Lange T (2012) Removal of shelterin reveals the telomere end-protection problem. Science (80- ) 336:593-597. https://doi.org/10.1126/science.1218498

31. Loayza D, De Lange T (2003) POT1 as a terminal transducer of TRF1 telomere length control. Nature 423:1013-1018 
32. Artandi SE, Attardi LD (2005) Pathways connecting telomeres and p53 in senescence, apoptosis, and cancer. Biochem Biophys Res Commun 331:881-890. https://doi.org/10.1016/j.bbrc.2005.03.211

33. Patel TNV, Vasan R, Gupta D, et al (2015) Shelterin proteins and cancer. Asian Pacific J Cancer Prev 16:3085-3090. https://doi.org/10.7314/APJCP.2015.16.8.3085

34. Linder B, Kögel D (2019) Autophagy in cancer cell death. Biology (Basel) 8:82.

https://doi.org/10.3390/biology 8040082

35. Su Z, Yang Z, Xu Y, et al (2015) Apoptosis, autophagy, necroptosis, and cancer metastasis. Mol Cancer 14:48. https://doi.org/10.1186/s12943-015-0321-5

36. Towers CG, Wodetzki D, Thorburn A (2020) Autophagy and cancer: Modulation of cell death pathways and cancer cell adaptations Autophagy and cancer. J Cell Biol 219:1-15.

https://doi.org/10.1083/jcb.201909033

37. Taji F, Kouchesfahani HM, Sheikholeslami F, et al (2017) Autophagy induction reduces telomerase activity in HeLa cells. Mech Ageing Dev 163:40-45. https://doi.org/10.1016/j.mad.2016.12.011

38. Zhang T, Shen S, Qu J, Ghaemmaghami S (2016) Global Analysis of Cellular Protein Flux Quantifies the Selectivity of Basal Autophagy. Cell Rep 14:2426-2439. https://doi.org/https://doi.org/10.1016/j.celrep.2016.02.040

39. Rao S, Tortola L, Perlot T, et al (2014) A dual role for autophagy in a murine model of lung cancer. Nat Commun 5:1-15. https://doi.org/10.1038/ncomms4056

40. Lee YJ, Jang BK (2015) The role of autophagy in hepatocellular carcinoma. Int J Mol Sci 16:2662926643. https://doi.org/10.3390/ijms161125984

41. Leal-Esteban LC, Fajas L (2020) Cell cycle regulators in cancer cell metabolism. Biochim Biophys Acta - Mol Basis Dis 1866:165715. https://doi.org/10.1016/j.bbadis.2020.165715

42. Ma X-H, Piao S, Wang D, et al (2011) Measurements of tumor cell autophagy predict invasiveness, resistance to chemotherapy, and survival in melanoma. Clin cancer Res 17:3478-3489. https://doi.org/10.1158/1078-0432.CCR-10-2372

43. Slavin SA, Leonard A, Grose V, et al (2018) Autophagy inhibitor 3-methyladenine protects against endothelial cell barrier dysfunction in acute lung injury. Am J Physiol Cell Mol Physiol 314:L388-L396. https://doi.org/10.1152/ajplung.00555.2016

44. Bharath LP, Agrawal M, McCambridge G, et al (2020) Metformin Enhances Autophagy and Normalizes Mitochondrial Function to Alleviate Aging-Associated Inflammation. Cell Metab 32:44-55.e6. https://doi.org/https://doi.org/10.1016/j.cmet.2020.04.015 
45. Maejima Y, Isobe M, Sadoshima J (2016) Regulation of autophagy by Beclin 1 in the heart. J Mol Cell Cardiol 95:19-25. https://doi.org/https://doi.org/10.1016/j.yjmcc.2015.10.032

46. Zhang Y, Qi H, Taylor R, et al (2007) The role of autophagy in mitochondria maintenance: characterization of mitochondrial functions in autophagy-deficient S. cerevisiae strains. Autophagy 3:337-346. https://doi.org/10.4161/auto.4127

47. Kamat PK, Kalani A, Kyles P, et al (2014) Autophagy of mitochondria: a promising therapeutic target for neurodegenerative disease. Cell Biochem Biophys 70:707-719. https://doi.org/10.1007/s12013-0140006-5

48. Benhamou Y, Picco V, Raybaud H, et al (2016) Telomeric repeat-binding factor 2: a marker for survival and anti-EGFR efficacy in oral carcinoma. Oncotarget 7:44236.

https://doi.org/10.18632/oncotarget.10005

49. Bryan TM, Marušić L, Bacchetti S, et al (1997) The telomere lengthening mechanism in telomerasenegative immortal human cells does not involve the telomerase RNA subunit. Hum Mol Genet 6:921-926. https://doi.org/10.1093/hmg/6.6.921

50. Muntoni A, Reddel RR (2005) The first molecular details of ALT in human tumor cells. Hum Mol Genet 14:R191-R196. https://doi.org/10.1093/hmg/ddi266

51. Celli GB, de Lange T (2005) DNA processing is not required for ATM-mediated telomere damage response after TRF2 deletion. Nat Cell Biol 7:712-718. https://doi.org/10.1038/ncb1275

52. Denchi EL, De Lange T (2007) Protection of telomeres through independent control of ATM and ATR by TRF2 and POT1. Nature 448:1068-1071. https://doi.org/10.1038/nature06065

53. Kumar R, Khan R, Gupta N, et al (2018) Identifying the biomarker potential of telomerase activity and shelterin complex molecule, telomeric repeat binding factor 2 (TERF2), in multiple myeloma. Leuk Lymphoma 59:1677-1689. https://doi.org/10.1080/10428194.2017.1387915

54. Dall'Armi C, Devereaux KA, Di Paolo G (2013) The role of lipids in the control of autophagy. Curr Biol 23:R33-R45. https://doi.org/10.1016/j.cub.2012.10.041

55. Hernandez-Diaz S, Soukup S-F (2020) The role of lipids in autophagy and its implication in neurodegeneration. Cell Stress 4:167. https://doi.org/10.15698/cst2020.07.225

\section{Tables}

Table 1. Terf1 and Terf2 forward and reverse primers. 


\begin{tabular}{lll}
\hline Genes & Primer (5à) \\
\hline Terf1 & Forward & AATAATAGACACTGGGGAGGTAGG \\
& Reverse & ATACTGTGTGATGTTGAGGTTTGG \\
Terf2 & Forward & CCATCCAAGCCTACCGTTCTCA \\
& Reverse & TGACCCACTCGCTTTCTTCTACA \\
\hline
\end{tabular}

\section{Figures}
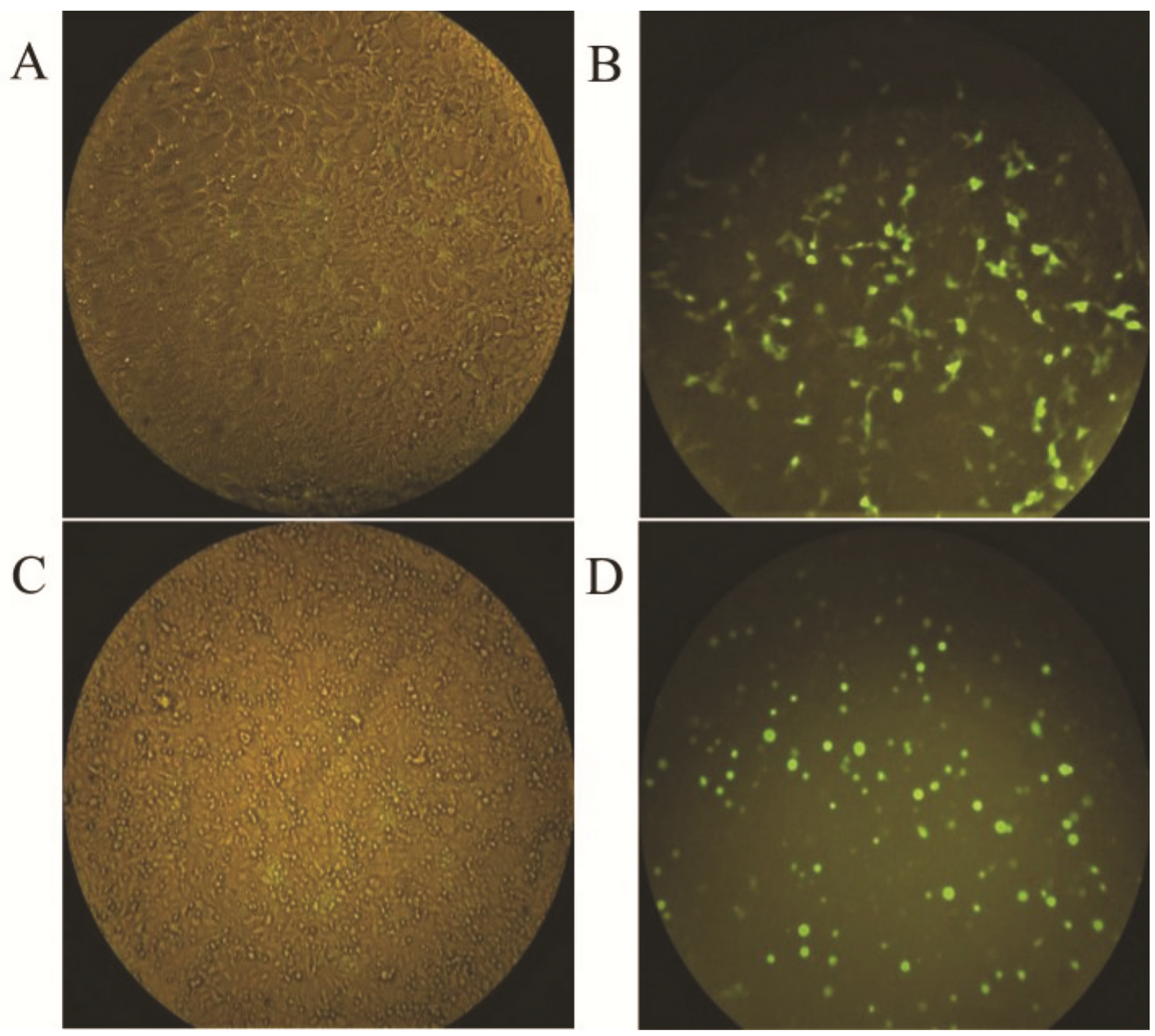

\section{$\mathrm{D}$}

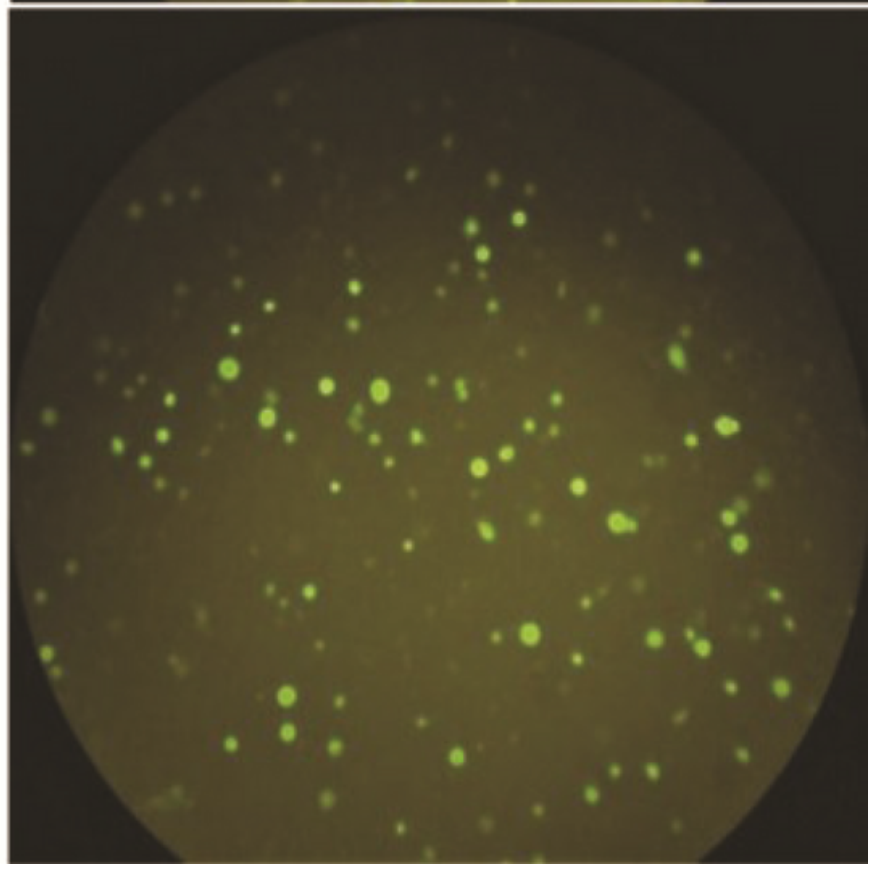

\section{Figure 1}

GFP fluorescent microscopic images of transfected U-2OS (A and B) and Huh7 (C and D) cell lines. 

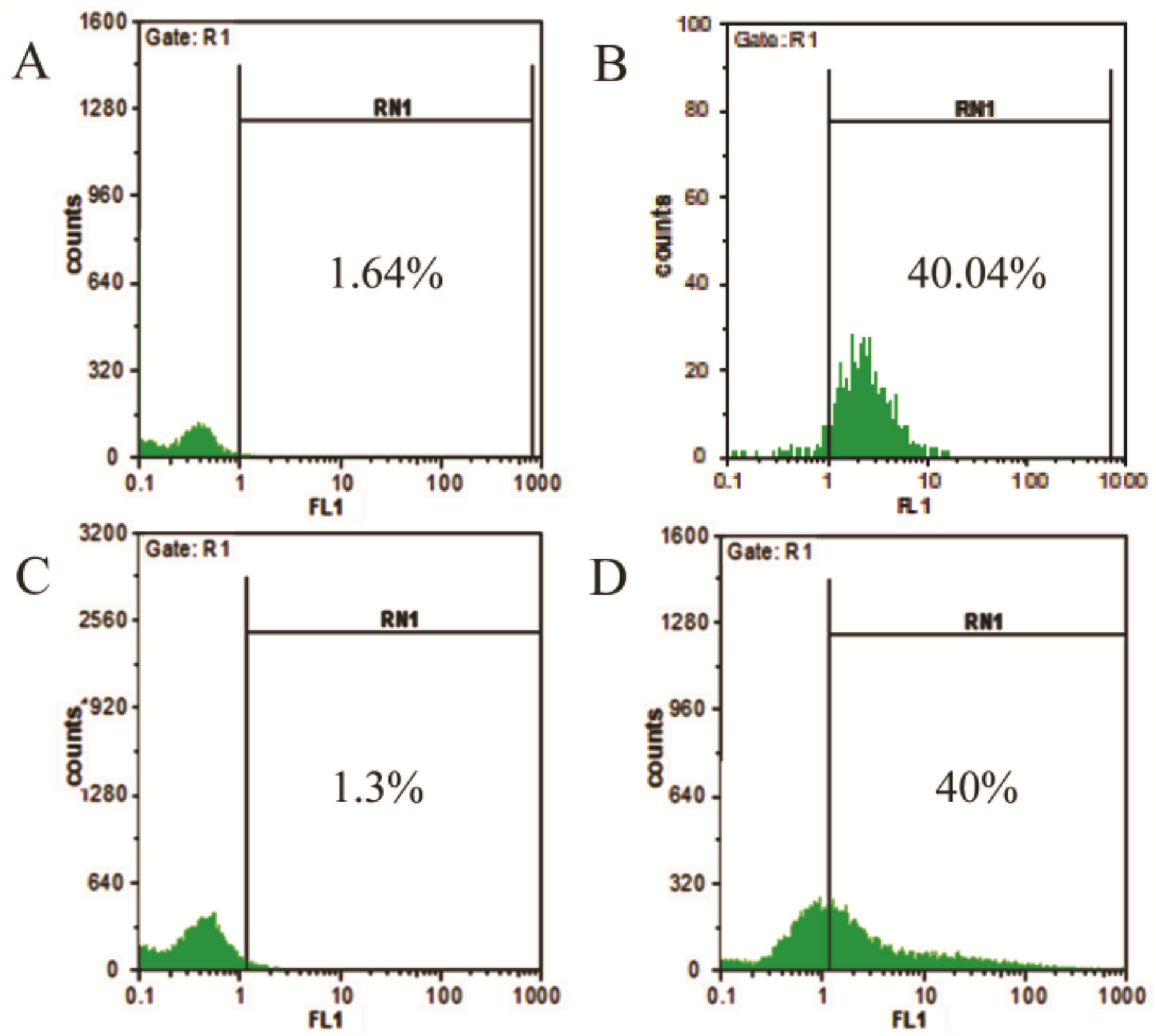

Figure 2

A) Flow cytometry results for GFP expression in (a) non-transfected U-20S (control group) (b) Beclin1transfected U-2OS (c) non-transfected Huh7 (control group) and (d) Beclin1-transfected Huh7 cell lines. B) Formation of LC3-II dots in (a) non-transfected U-20S (control group) (b) Beclin1-transfected U-2OS (c) non-transfected Huh7 (control group) and (d) Beclin1-transfected Huh7 cell lines. 

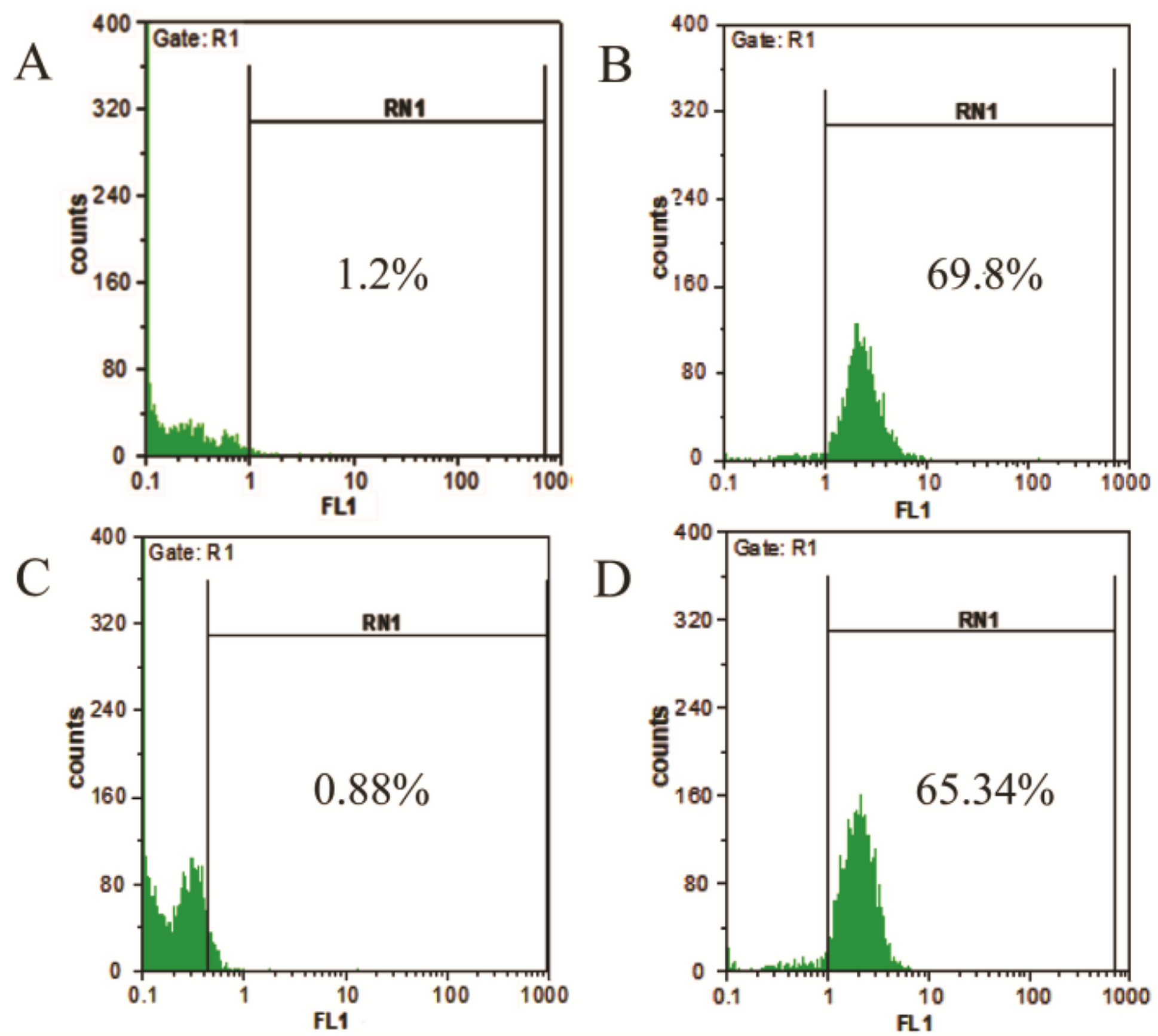

Figure 3

A) Terf1 expression in U-20S and Huh7 cell lines after 24 and $48 \mathrm{~h}$ treatment with (Lipo) Lipofectamine 2000, (PIsBec1) Beclin1-containing plasmid, (3-MA) 3-methyladenine, and (Met) metformin ( $\left.{ }^{*} p<0.05\right)$. B) Terf2 expression in U-20S and Huh7 cell lines after 24 and 48 hours treatment with (Lipo) Lipofectamine 2000, (PlsBec1) Beclin1-containing plasmid, (3-MA) 3-methyladenine, and (Met) metformin ( $\mathrm{p}<0.05$ ). 


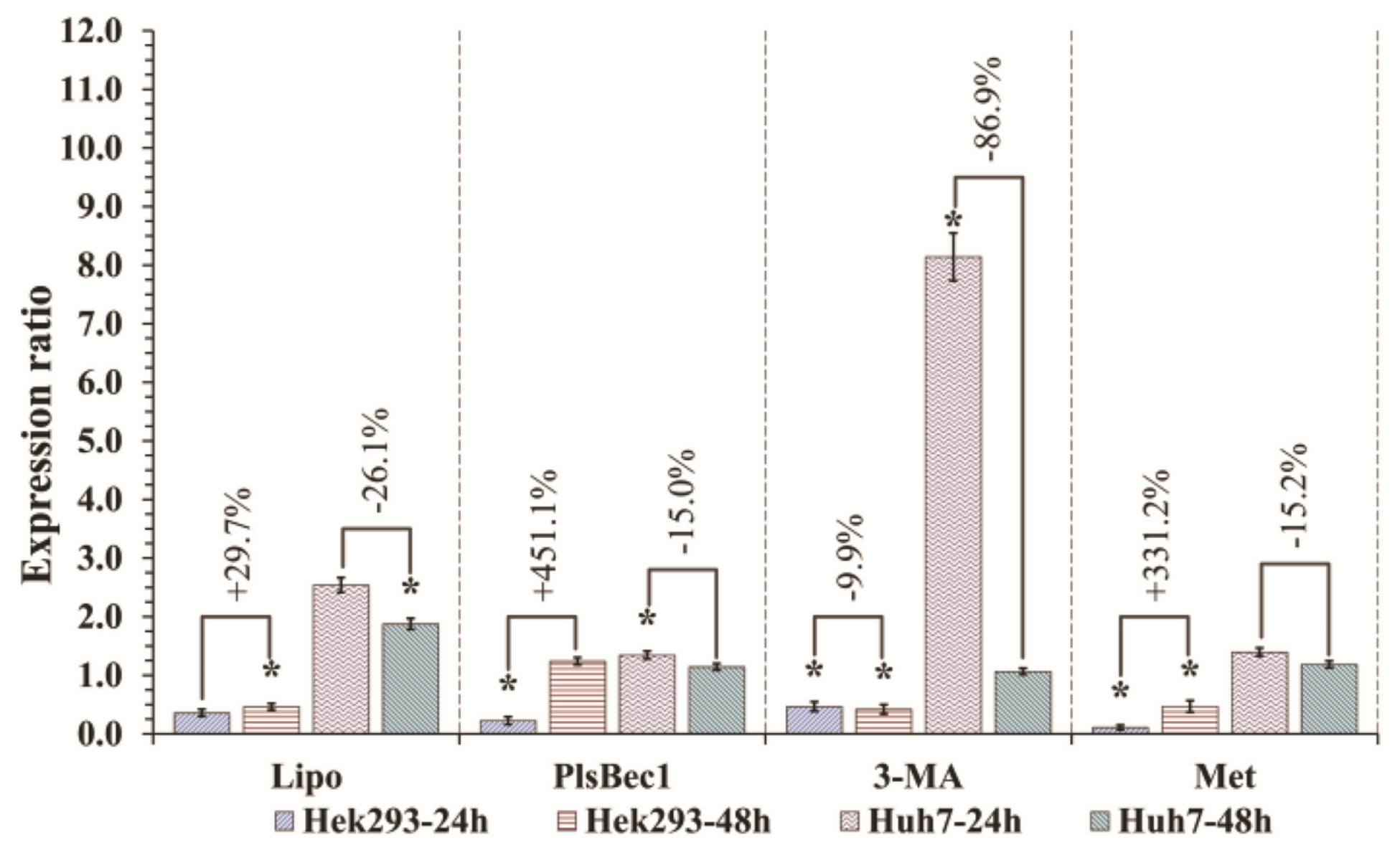

\section{Figure 4}

Pathways for autophagy and telomeric shelterin protein (Terf1 and Terf2) crosstalk in (1) positivetelomerase cell lines and (2) negative-telomerase (ALT positive) cell lines. The dual role of autophagy (malignant cells suppressor or supporter) depends on oncogenes that are present in malignant cells. 


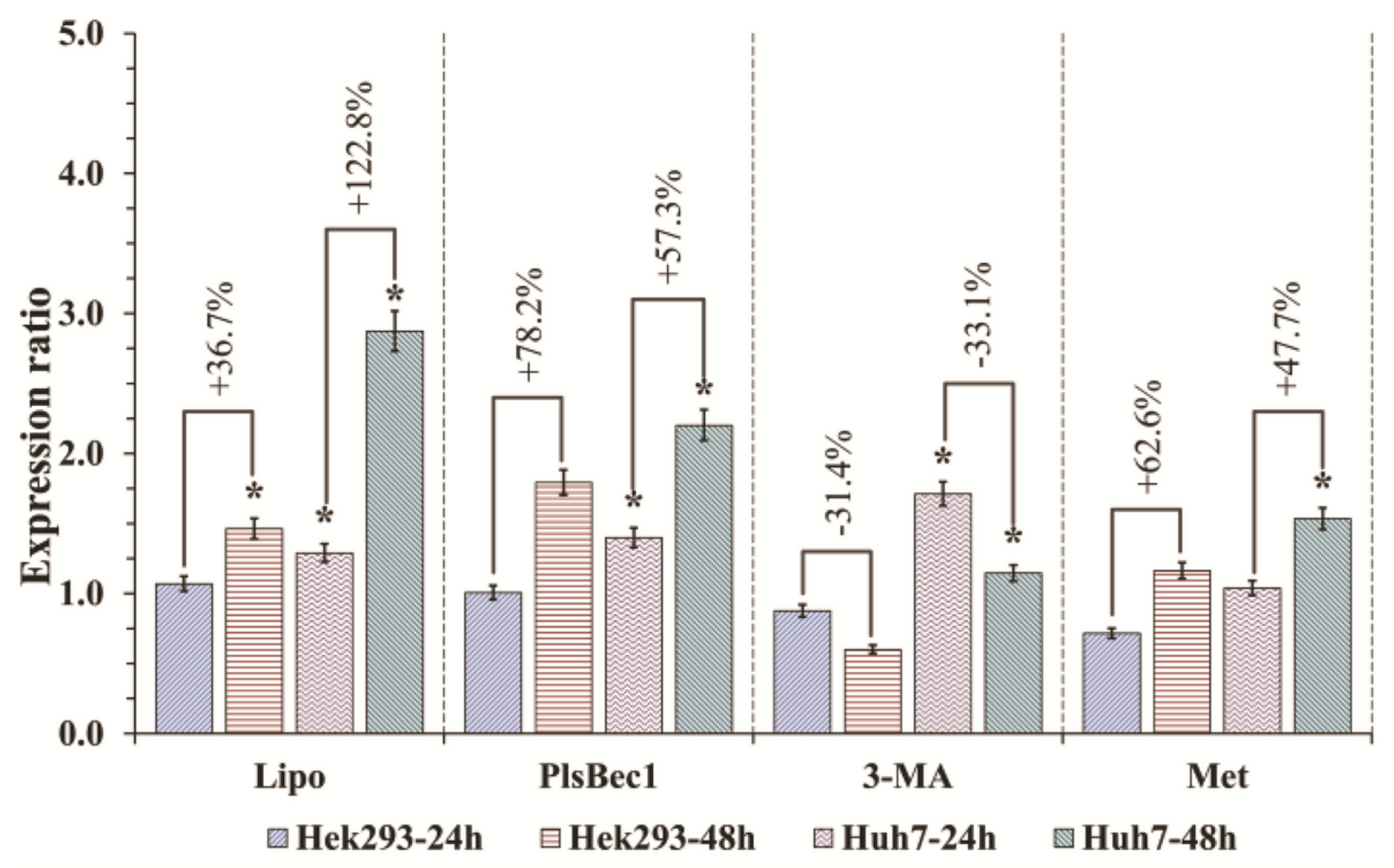

Figure 5

Terf2 expression had similar variations for both U-20S and Huh7 cell lines (Fig. 5). The different treatment for $24 \mathrm{~h}$ led to a significant improvement in the expression level for all treatments that could have a positive effect on Terf2 upregulation. 3-methyladenin treatment displayed its intrinsic and expectative downregulating effect on Terf2 expression, which resulted in a $31.4 \%$ and $33.1 \%$ decrease in Terf2 expression level for U-20S and Huh7 cells, respectively. 


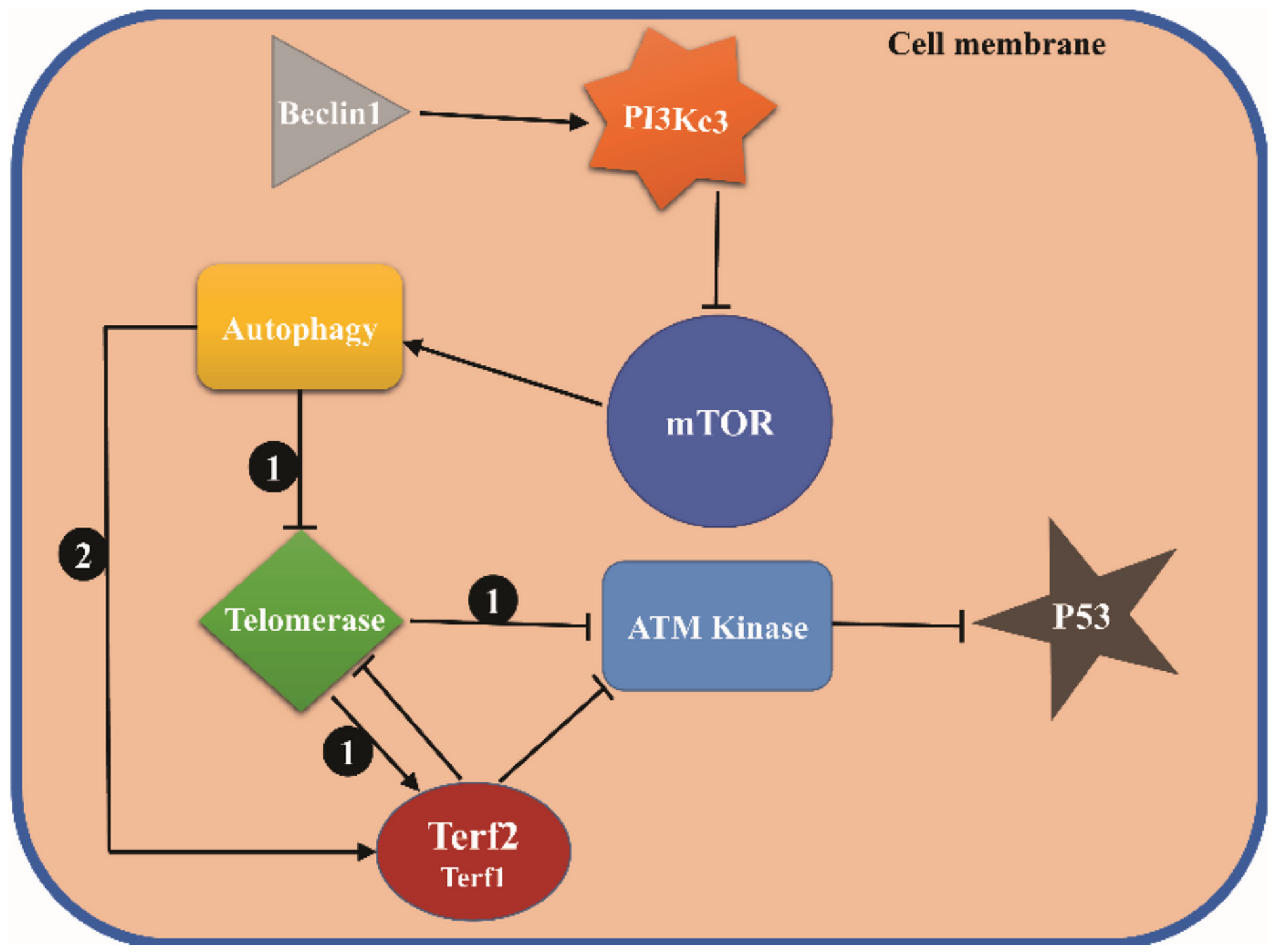

Figure 6

Although autophagy dysfunction can start carcinogenesis, it is not enough for malignancy because malignancy occurrence in this pathway depends on other oncogenes such as p53/ Auxin response factors (ARF)/ Ataxia-telangiectasia mutated (ATM) (Fig. 6).

\section{Supplementary Files}

This is a list of supplementary files associated with this preprint. Click to download.

- GA.tif 